\title{
Influence of Food Attributes on Purchasing Behavior of Food Deseret Residents in Eastern Greensboro, NC: Multidimensional Scaling Approach
}

\author{
Terrence Thomas* and Freda Dorbu \\ Department of Agribusiness, Applied Economics \& Agri science Education, North Carolina A\&T State University, USA
}

*Corresponding author: Terrence Thomas, Department of Agribusiness, Applied Economics and Agri science Education, College of Agriculture and Environmental Sciences, North Carolina A\&T State University, Greensboro, North Carolina, USA.

To Cite This Article: Terrence Thomas, Freda Dorbu. Influence of Food Attributes on Purchasing Behavior of Food Deseret Residents in Eastern Greensboro, NC: Multidimensional Scaling Approach. 2020 - 11(1). AJBSR.MS.ID.001593. DOI: 10.34297/AJBSR.2020.11.001593.

Received: October 27, 2020; Published: 眥 December 01, 2020

\begin{abstract}
Consumers purchase food because of the perceived nutritional advantages, taste, family, cultural preferences, and previous purchase habits. This study aims at using multidimensional scaling to identify the similarities and or dissimilarities between the variables:

(1) affordability and taste

(2) high nutritional value/ high level of food hygiene and

(3) freshness/reasonable level of nutrition / food hygiene based on the underlying dimensions used by Eastern Greensboro residents in rating these variables. [1]

Sampling protocol was used to determine the appropriate sample size for this study. Survey Sampling Incorporated, from whom we purchased the sample, used the sampling protocol to draw a random sample from the population of Eastern Greensboro, North Carolina. Data was collected by trained enumerators via telephone survey using the Survey Monkey platform.

We used multidimensional Scaling to analyze and translate the data onto a perceptual map to facilitate visualization of the differences between the variables and to determine the dimensions underlying the observed orientation. Results show that food desert residents may be using the inferred underlying dimensions: 1) desirability and 2) accessibility to make judgement about the food attributes investigated in this study. Results further show that the variables: affordability/taste, and high nutritional level/high level of food hygiene are closely oriented on the perceptual map. This implies that consumers may be using affordability/taste as proxy for high nutritional value/high level of food hygiene since it may be easier to recognize and assess the attribute taste/affordability than it is to recognize and assess high nutritional level/high level of food hygiene.
\end{abstract}

Keywords: Preference, Similarity or Dissimilarity, Multidimensional scaling, Food desert residents, Nutritional, Public health tremendously, Artificial, Supermarkets, Hungriest State, Consolidation, Centralization

\section{Introduction}

Adequate consumption of nutrients affects public health tremendously [2]. Financial constraints and limited access to supermarkets impede consumption of required amount of nutrient by food desert residents [3-4] indicated food choice decisions and food consumption play crucial roles in health management. However, consumers purchase food based on the attributes they see or perceive. The decision to purchase a product is significantly determined by consumer perceived values [5]. They purchase food because of the perceived nutritional advantages, taste, family and cultural preferences, and previous purchase habits [6] and cost; [7].
A sample of the literature shows that the rate at which consumers are demanding foods that are safer, healthier, palatable, and environmentally or animal friendly is increasing [8-9]. Concerns about safety among consumers [10] has increased interest in consuming fresh (natural) foods rather than processed (artificial) foods [11].

However, food desert residents consume unhealthy diets and experience an increased risk of obesity [11]. A report from the Economic Research Service of the U.S Department of Agriculture described a food desert as a census tract where most of the 
residents are low-income earners and they have less access to grocery stores [12]. The phenomenon of "food deserts" is because of the consolidation and centralization of the food system [13]. Food desert residents must travel one mile or more to access grocery stores. In the year 2015, in the U.S., there were more than 20,000 census tracts with citizens earning low income and residing between 0.5 miles to 10 miles away from supermarkets.

\section{Food Deserts in North Carolina}

North Carolina is the ninth hungriest State in the U.S. [14]. A report from the North Carolina Alliance for Health (2014) stated that more than 349 food deserts exist in 80 counties in North Carolina. The research area, Eastern Greensboro, is in Guilford County, North Carolina. Guilford County has 24 food desert census tracts located mostly in areas with high-minority populations, such as Southeast and East Greensboro and Central High Point. The absence of supermarkets encourages the dependence on convenient stores and fast-food outlets (Dubowitz et. al, 2015), resulting in the consumption of unhealthy diets of low or no nutrient value such as sugar-enriched beverages, candy, alcohol, cakes, and other delicacies [15]. Supermarkets provide an array of healthy choices at the lowest price [13] and access to supermarkets correlates with reduction in rates of obesity occurrence (Michimi \& Wimberly, 2010). In the study area, there have been initiatives to improve access, which include establishing a Community Co-op grocery store and an urban farm that produces fresh vegetables, in addition to providing nutrition education classes for residents. Unfortunately, the grocery store was closed in 2019 due to low patronage [16], however, the other two initiatives continue to operate. The impetus for this study is to investigate and uncover the underlying dimensions that influence how residents evaluate and use food attributes in making food purchase decisions.

\section{Food Attributes (variables)}

A clear understanding of consumer purchase behavior will enable extension educators and public health authorities to assist food desert residents in making a conscious effort to use information about food attributes to make healthier food purchase decisions. Below is a summary of consumers perception of food attributes investigated in this study

Taste: Consumers develop taste for food based on the perception formed because of the stimulation of the gustatory nerve. Taste highly affects food choice. Effect of taste on food consumption is dependent on the age and sex of the consumer [17]

Price/affordability: The amount of money a consumer is willing to sacrifice to obtain a product [5]. Consumers sacrifice quality of a food product for affordability. However, manipulation of the price of a product that gives satisfaction to consumers can leverage consumer willingness to pay for a product [18].
Freshness: Basic agricultural products that have not been processed are identified as fresh foods [11]. A fresh vegetable or fruit is a tumescent product showing no indication of shrinkage or crumbling of cells and with no sign of deterioration (ISO 7563, 1998). Cardello \& Schutz (2003) suggested that development of freshness perceptions is impacted by the kind of food items, and that the understanding of freshness differ for everyone. The increase in the consumption of fresh food is due to the rise in food consumption and consumer demand for food that is healthy (Franz et al., 2010). Consumer concern for food safety (Si \& Scoot, 2017), the health benefits [19], and nutrition (Shine, O'Reilly, \& O'Sullivan, 1997) are driving consumers to purchase natural foods instead of synthetic food products [19]. Consumers assume fresh foods are healthy because of their fresh form (Boatemaa, Delali, \& Aikins, 2018).

Nutrition: Leathwood et al., (2007) stated that nutrition and health concerns are gradually becoming major factors that stimulate consumers' choice of food enabling them to make wellinformed dietary decisions. The health consciousness of consumers in recent times has led to the rise in demand of functional foods such as milk and processed diary food products because such foods are considered nutritious. Consumer initiative for adopting nutritious and healthy lifestyle has a positive impact on food preferences and purchase behavior (Kaur et al., 2017). Intake of recommended nutrient amount may be linked with disease risk reduction.

Health: Factors that motivate consumer purchase of healthy products are concerns about body mass index, diet status, weight, health and prevention of chronic diseases, lifestyles, personality traits [20]. While healthy foods are assumed to contain less calories than the actual amount (Carels et al., 2006), unhealthy foods are perceived to contain more calories than the actual amount (Booth, 1987). However, healthiness of food is not based only on calorific content but on multiple nutritional attributes [21].

\section{Methodology}

\section{Data collection and sampling method}

The target group for the study was residents of census tracts classified as food deserts in Eastern Greensboro, North Carolina. Dilman et al. (2009) sample size formula was used to determine the appropriate sample size for the study. The sample was purchased from Survey Sampling Inc. They drew a random sample from the defined study area (Eastern Greensboro, NC) based on the sampling protocol researchers provided. Three enumerators were trained to collect data via telephone survey using the Survey Monkey platform. The questionnaire focused on eliciting responses regarding the extent to which the various food attributes influenced food purchases. A five-point Likert type scale was used to measure the responses; five (5) representing "always" and one (1) representing "never". 


\section{Data analysis method}

The statistical analytical tool used for the data analysis is PROXSCAL multidimensional Scaling via SPSS version 20. Multidimensional scaling was chosen because it creates a perceptual map showing the spatial orientation of the variables. The differences in the spatial orientation among the variables is based on inferred underlying dimensions. Data collected was projected onto a spatial graph showing proximities among the variables oriented in two-dimensional space. The analysis used two hundred and eighty-eight responses following data cleaning.

The data format and the matrix source were selected. The proximity transformation used was "Ordinal" with untie tied observations option, the shape is "full matrix" and the proximities selected is "dissimilarities." The minimum and maximum dimensions used was 2 . There were no restrictions placed on the model. Torgerson style was selected for the initial configuration and a stress convergence of 0.0001 with maximum iterations of 100. The output of the analysis was displayed on a common space showing the distances and the transformed proximities between the objects. History of the iteration process and the stress decomposition were also included in the output. The stress level, the Dispersion Accounted For (D.A.F) and the Tucker's Coefficient of Congruence values were used to determine the goodness of fit of the data.

\section{Criteria for validity and reliability of multidimensional} scaling

The number of dimensions chosen should be appropriate for the data set ensuring that there is no misrepresentation of the data set. Two dimensions are usually used for the representation of results for easy comprehension of results. Secondly, stress level determines the fitness of the multidimensional scaling model used. Borgatti (1997) explains stress as "the degree of correspondence between the distances among points implied by the MDS map and the matrix input by the user. Calculation of stress level followed Kruskal (1964) formulation as: High stress levels, for example, a level of $20 \%$ indicates the unfitness of the model whereas a $2.5 \%$ stress indicates an excellent goodness of fit.

\section{Results}

Non-metric multidimensional scaling output reflects the correlation between the distances and the proximity rankings of the objects [22]. Table 1 shows the distances between the variables. Spatial orientation of the variables shows that the distance between the variables: affordability/taste, and high nutritional value/d high level of food hygiene is 0.921 , and the proximity (Table 2) is 0.925 . These figures are the lowest figures for distances and proximities and there is no significant difference between them (Table $1 \& 2$ ). The variables affordability/taste, and high nutritional level/high level of food hygiene are closer together at 0.921 and a proximity of 0.925 . These variables are perceived to be similar compared to the matrix between the other variables (Figure 1). The perceptual map shows that Affor_taste and HNuv_Hlh seem to have the same value as Affor-taste on dimension one but different values on dimension 2. Although HNuv_Hlh recorded a negative coordinate on dimension 2 , it has a high positive point on dimension 1. Affor_taste assumed high positive coordinates for both dimensions.

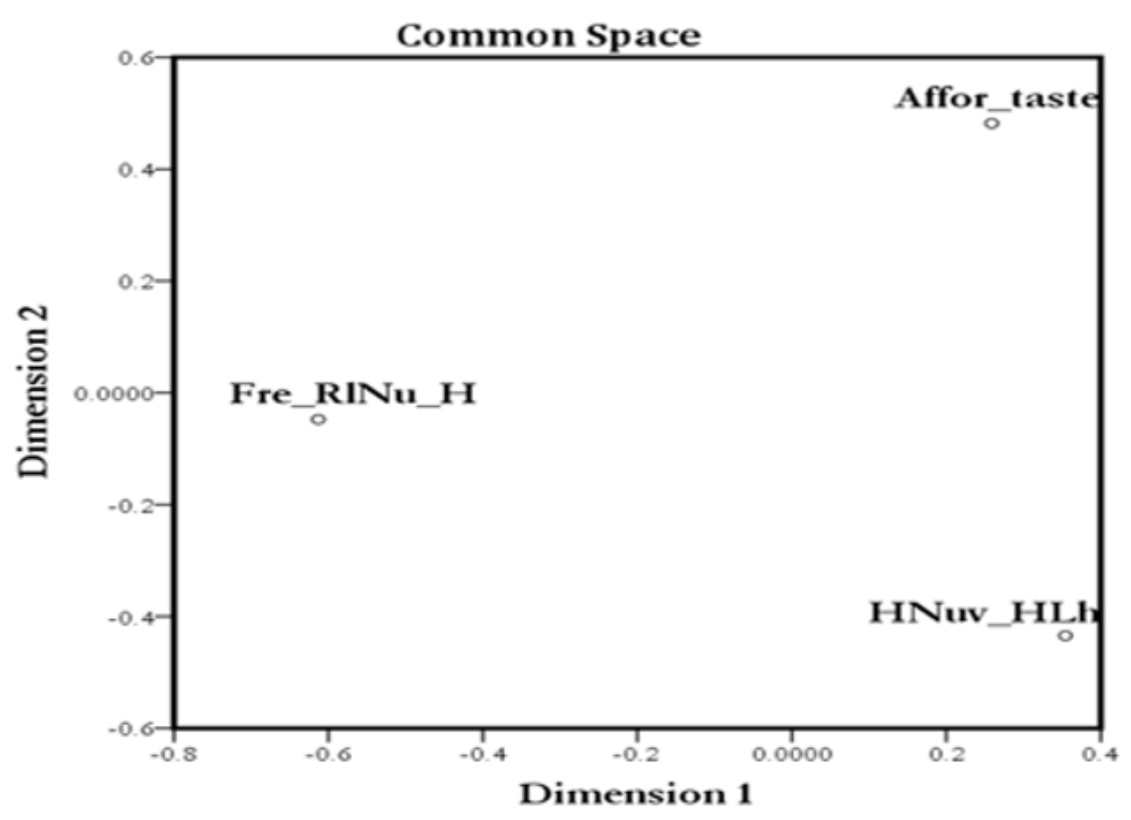

Figure 1: Attributes influencing consumer food purchase. 
Table 1: Distances between the variables.

\begin{tabular}{|c|c|c|c|}
\hline & Affordability / Taste & $\begin{array}{c}\text { High Nutritional Level /High } \\
\text { Level of Food Hygiene }\end{array}$ & $\begin{array}{c}\text { Freshness, Reasonable Level of } \\
\text { Nutrition / Food Hygiene }\end{array}$ \\
\hline Affordability / Taste & 0 & & \\
\hline $\begin{array}{c}\text { High Nutritional Level /High Level } \\
\text { of Food Hygiene }\end{array}$ & 0.921 & 0 & 0 \\
\hline $\begin{array}{c}\text { Freshness, Reasonable Level of } \\
\text { Nutrition / Food Hygiene }\end{array}$ & 1.02 & 1.042 & 0 \\
\hline
\end{tabular}

Table 2: Transformed proximities between variables.

\begin{tabular}{|c|c|c|c|}
\hline & Affordability / Taste & $\begin{array}{c}\text { High Nutritional Level /High } \\
\text { Level of Food Hygiene }\end{array}$ & $\begin{array}{c}\text { Freshness, Reasonable Level of } \\
\text { Nutrition / Food }\end{array}$ \\
\hline Affordability / Taste & 0 & & \\
\hline $\begin{array}{c}\text { High Nutritional Value /High Level } \\
\text { of Food Hygiene }\end{array}$ & 0.925 & 0 & 0 \\
\hline $\begin{array}{c}\text { Freshness, Reasonable Level of } \\
\text { Nutrition / Food Hygiene }\end{array}$ & 1.024 & 1.046 & \\
\hline
\end{tabular}

Consumers perceive Affor_taste and HNuv_Hlh cluster close together, hence they have similar impact on consumer food purchase, given the psychological yardstick of dimension one as the basis for consumer judgement. Fre_RINu_H, however, is not highly rated on either dimension. The goodness of fit of the results was attained after six iterations. A stress level of 0.091, Dispersion Accounted For (D.A.F) value of 0.99167, and Tucker's Coefficient of Congruence of 0.99583 indicate the goodness of fit of the data. Similarity between the variables was assessed using Tucker's Coefficient of Congruence. It is referred to as the unadjusted correlation whose value ranges between -1 and +1 . Whereas a value of 0.95 indicates a higher level of similarity [23], a value greater than 0.95 indicates that the variables are identical. Although the Coefficient of Congruence value for the study is 0.99583, implying that the variables are identical, Fre_RINu_H is dissimilar or quite different from the other two variables on both dimensions.

\section{Discussion and Conclusion}

Results from the analysis show that consumers ranked affordability/taste highly on both dimensions 1 and 2. Dimension 1 is inferred to be based on desirability of food attributes and dimension 2 is inferred to be based on degree of accessibility. Affordability/taste ranking high on dimension 2 indicates that the ability of consumers to access and consume food is highly influenced by the price and taste of the food. Consumers tend to buy food that is tasty and inexpensive, encouraging the consumption of less expensive unhealthy food. This pattern of food purchase behavior may be reflecting the low-income status of food desert residents. Additionally, because food desert resident lives in a poor food environment, they are conditioned to prefer inexpensive tasty food items-food items that are affordable and tasty. Socioeconomic status is one variable among others that affects the decision to consume food after the establishment of taste feedback [24]. The ability to merge price and taste can facilitate a positive influence on food choice [25]. Therefore, discounting the price of healthy food can lead to consumption of healthy food. Affordability/taste was also highly ranked by consumers along dimension 1 , implying that consumers highly desire food that are affordable and tasty [26]. The perceptual map also shows that, consumers ranked high nutritional level/high level of food hygiene high on dimension 1, indicating that consumers highly desire nutritious and healthy foods. This implies that consumers consider the nutritional value of food when making food purchase decisions. However, consumers ranked high nutritional level/high level of food hygiene on dimension 2, probably because it is not easy to assess the nutritional /hygiene level of foods, and that they perceive nutritious foods are not accessible because of where they live. [27-29]

We also note that the orientation on the perceptual map indicates that affordability/taste, and high nutritional level/high level of food hygiene cluster together along dimension 1 [30]. This implies that consumers may be using affordability and taste as a proxy for high nutritional level and high level of food hygiene because they find it difficult to assess the hygienic and nutritional value of a product. Freshness, reasonable level of nutrition/food hygiene ranked lowly on both dimension 1 and dimension 2. On dimension 1, consumers are not highly desirable of freshness and reasonable level of nutrition and food hygiene during purchases, probably because it is not easy to assess the freshness of all food items since the nature (raw or processed) of food items is not defined. Also, on dimension 2 [31]. The rank of freshness, reasonable level of nutrition/food hygiene indicate the difficulty of assessing freshness and nutrition as previously discussed. However, defining the nature (raw or processed) of the food items could help consumers properly rank the influence of freshness on their purchases.

Given, residents of food deserts seem to employ the inferred dimensions: 1) desirability of the food attribute and 2) accessibility(ease of assessing the attribute and availability of food with attribute for making purchasing decisions), policy makers should endeavor to put in place those policies that would make 
food more available and desirable to food desert residents [32,33]. One approach could entail modifying the food environment to make healthy food accessible and affordable both in terms of availability and ease of assessing the nutritional value of all foods made available [34,35]. This could include local food production and nutrition education programs that employ hand-on approaches to train residents to read and evaluate food labels, how to shop wisely and how to prepare nutritious and tasty meals. All such efforts should consider that residents have been conditioned by the food desert environment to eat tasty and inexpensive unhealthy food. Therefore, approaches should be designed to meet residents where they are and try to graft the desirable change in behavior onto some aspect of current behavior [36-38].

\section{Reference}

1. Dillman D, Phelps G, Tortora R, Swift K, Kohrell J, et al. (2009) Response Rate and Measurement Differences in Mixed-Mode using Mail, Telephone, Interactive Voice Response (IVR), and the Internet 38(1): 1-18.

2. Leitão Gonçalves R, Carvalho Santos Z, Francisco AP (2017) Commercial Bacteria and Essential Amino Acids Control Food Choice Behavior and Reproduction 15(4): e200862.

3. Larson N, Story M, Nelson MC (2009) Neighborhood Environments: Disparities in Access to Healthy Foods in the U.S. American Journal of Preventive Medicine 36(1): 74-81.

4. Kuo S, Lin H (2019) Effects of Food Environments and Eating Environments on Consumers' Food Consumption Volume. Journal of Food Quality.

5. Zeithaml VA (1988) Consumer Perceptions of Price, Quality, and Value: A Means-end Model and Synthesis of Evidence. Sage Journal 52(3): 2-22.

6. Shepard R (1989) Factors Influencing Food Preferences and Choice. In Handbook of the Psychophysiology of Human Eating 3-24-26.

7. Yang J, Gu Y, Cen J (2011) Festival tourists' emotion, perceived value, and behavioral intentions: A test of the moderating effect of festivalscape. J Convention Event Tourism 12(1): 25-34.

8. Gao Z, Schroeder T, Yu X (2010) Consumer willingness to pay for cue attribute: The value beyond its own. Journal of International Food \& Agribusiness Marketing 22(1): 108-124.

9. Krasnodebski A, Cieslik J (2001) Studies on consumer preferences on an example of dairy products. In: Zbornik vedeckych prac III Konkurencieschopnost vybranych agrarnych komodit SR pred vstupom do EU. SPU Nitra 53-57.

10. McCarthy M, Brennan M, Kelly AL, Ritson C, Boer M, et al. (2007) who is at risk and what do they know? Segmenting a population on their food safety knowledge. Food Quality and Preference 18(2): 205-217.

11. Cummins S (2014) Food Deserts. The Wiley Blackwell Encyclopedia of Health, Illness, Behavior, and Society 562-564.

12. (2013) U.S Department of Agriculture, Economic Research Service. Food Access Research Atlas, Washington DC.

13. Hendrickson M, Heffernan W, Howard P, Heffernan J (2001) Consolidation in food retailing and dairy. British Food Journal 103(10): 715-728.

14. Tru T (2018) Why are people hungry in North Carolina?

15. Pearce J, Hiscock R, Blakely T, Witten K (2008) the contextual effects of neighbourhood access to supermarkets and convenience stores on individual fruit and vegetable consumption. J Epidemiology and Community Health 62(3): 198-201.

16. Killian J (2019) in one of NC'S many food deserts a co-op grocery store closes.
17. Drewnowski A (1997) Taste preference and food intake. Annual Review of Nutrition 17: 237-253.

18. Nunes JC, Boatwright P (2004) Incidental prices and their effect on willingness to pay. Journal of Marketing Research 41(4):457-466.

19. Buch S, Pinto S, Aparnathi KD (2014) Evaluation of efficacy of turmeric as a preservative in paneer. Journal of Food Science and Technology. Document Details 51(11): 3226-3234.

20. Carels RA, Konrad K, Harper J (2007) Individual differences in food perceptions and calorie estimation: An examination of dieting status, weight, and gender 49(2): 450-458.

21. Fernandes AC, de Oliveira RC, Rodrigues VM, Fiates GMR, da Costa RP, et al. (2015) Perceptions of University students regarding calories, food healthiness, and the importance of calorie information in menu labelling. Appetite 91: 173-178.

22. Groenen P, Borg I (2015) Multidimensional Scaling II.

23. Jensen A (1998) the g factor: The Science of Mental Ability. Westport CT: Praeger 99-100.

24. Drewnowski A (1997) Tast e preference and food intake. Annual Review of Nutrition 17: 237-253.

25. Baudry J, Péneau S, Allès B, Touvier M, Hercberg S, et al. (2017) Food choice motives when purchasing in organic and conventional consumer clusters: focus on sustainable concerns. Nutrients 9(2): 88.

26. Berger J, Heath C (2007) Where Consumers Diverge from Others: Identity Signaling and Product Domains. Journal of Consumer Research 34(2): 121-134.

27. Boer J, Hoogland CT, Boersema JJ (2007) towards more Sustainable Food Choices: Value Priorities and Motivational Orientations 18(7): 985-996.

28. Castress, P (2015) Informed food choices for healthier consumers. The European Consumer Organization.

29. Haard NF (1992) Control of Chemical Composition and Food Quality Attributes of Cultured Fish. Food Research International 25(4): 289-307.

30. Jerome NW (1982) Dietary Patterning and Change: A Continuous Process. Contemporary Nutrition Newsletter. General Mills, Inc 7(6).

31. Jung K, Takane Y (2015) International Encyclopedia of the Social and Behavioral Sciences. 2nd Ed.

32. Michels KB, Bloom BR, Riccardi P, Rosner BA, Willett WC, et al. (2008) A study of the importance of education and cost incentives on individual food choices at the Harvard School of Public Health Cafeteria 27(1): 6-11.

33. Monroe KB, Krishnan R (1985) the Effect of Price on Subjective Product Evaluations. In: Jacoby J, Olson JC (Eds.) Perceived Quality: How Consumers View Stores and Merchandise. D.C. Heath and Company, Lexington, MA 209-232.

34. Sparks A, Bania N, Leete L (2009) Finding Food Deserts: Methodology and Measurement of Food Access in Portland, Oregon. National Poverty Center/USDA Economic Research Service.

35. Asp EH (1999) Factors Affecting Food Decisions made by Individual Consumers. ScienceDirect 24(2-3): 287-294.

36. Wansink B, Park SB (2001) at the moves: How external cues and perceived taste impact consumption volume. Food quality and preference 12(1): 69-74.

37. Wrigley N, Warm D, Margetts B (2003) Deprivation, diet, and food-retail access: findings from the Leeds 'food deserts' study. Environment and Planning 35(1): 151-188.

38. Smoyer Tomic KE (2006) Food deserts in the prairies? Supermarket accessibility and neighborhood need in Edmonton, Canada. The Professional Geographer 58(3): 307-326. 